\title{
Estimation of clotting and cutting times in sheep cheese manufacture using NIR light backscatter
}

\author{
N. Nicolau ${ }^{1} \cdot$ M. Buffa ${ }^{1}$ - D. J. O'Callaghan ${ }^{2}$ • \\ B. Guamis ${ }^{1}$ - M. Castillo ${ }^{1}$
}

Received: 18 July 2014 / Revised: 11 March 2015 / Accepted: 16 April 2015 /

Published online: 7 May 2015

(C) INRA and Springer-Verlag France 2015

\begin{abstract}
During sheep cheese manufacturing, the time determination for such important steps as clotting and cutting time relies on the experience of the cheese maker or, alternatively, on predetermined reaction times. However, efficient control of coagulation requires a rigorous, objective, inline method to select the optimum time to proceed with clotting and cutting time. Therefore, a near-infrared (NIR) light backscatter fiber optic sensor was implemented in order to monitor coagulation of sheep milk and assess the possibility of estimating both clotting and cutting times during the manufacture of sheep's cheese. A randomized block experiment with three replications was designed to determine optical, rheological, and visual coagulation parameters in sheep milk using four enzyme concentrations. The optical response of the sheep milk was found to be greater than in goat milk (15-20\%) but lower than cow milk (30-50\%). The standard error for the optical parameters during the coagulation of sheep milk was lower than those observed for the visual parameters. Optical variables were strongly correlated with both visually and rheologically defined coagulation parameters. Rheologically and visually determined clotting and cutting times were successfully predicted using only one optical parameter. Our results suggest that optical parameters generated from the NIR light backscatter profile adequately respond to the kinetic changes induced by varying the concentration of enzyme and that prediction of rheologically determined cutting time using NIR light backscatter is more precise than prediction of visually determined cutting time, i.e., $~ 50 \%$ lower SEP.
\end{abstract}

N. Nicolau

natalia.nicolau@uab.cat

1 Departament de Ciencia Animal i dels Aliments, Edifici V. Facultat de Veterinària, Universitat Autònoma de Barcelona, Centre Especial de Recerca Planta Tecnologia dels Aliments (CERPTA), Bellaterra, Cerdanyola del Vallés, Barcelona, Spain 08193

2 Teagasc, Moorepark Food Research Centre, Fermoy, Co, Cork, Ireland 
Keywords Cheese $\cdot$ Clotting and cutting time $\cdot$ Light backscatter $\cdot$ NIR $\cdot$ Rheology and prediction

\section{Introduction}

Milk coagulation is the initial step in the manufacture of many dairy products and can be induced by acidification or by rennet addition. In hard cheeses (rennet-induced coagulation), optimal control of both clotting and cutting times is critical (Castillo et al. 2006). Cutting time greatly affects moisture, yield, and quality of cheese as well as whey fat losses. The selection of cutting time depends on rheological and microstructural properties of gels, such as coagulum firmness and rearrangement capability that, in turn, depend on coagulation factors, milk composition, and milk pretreatment (Jimenez-Marquez et al. 2005; Castillo 2006; Rovira et al. 2013). Cutting the curd too early causes a poor yield because the gel is too soft at cutting, which results in curd fines and whey fat losses (Castillo et al. 2003; Hori 1985; Payne et al. 1993). However, cutting the curd too late results in poor quality because the curd is too firm at cutting and syneresis is inhibited, which results in a high-moisture cheese. As there are numerous factors that influence the gel formation and have an effect on the cutting time, cutting the coagulum at a pre-determined time is questionable even if that is the way it is done in many cheese plants (Gunasekaran and Ay 1996). On the other hand, cutting the curd based on empirical inspection of the gel by the operator is only acceptable if the evaluation is made properly (Hori 1985). Optimal selection of cutting time is more important for small and less mechanized cheese plants, such as farmhouse sheep cheese manufacturing, most of them accounting for protected cheese denominations, such as P.D.O Manchego, P.D.O Torta del Casar, P.D.O. Torta de La Serena, and, P.D.O. Zamorano, among others (Dubeuf et al. 2010), where large differences in milk composition are observable during the lactation period (Van Hooydonk and Van den Berg 1988).

A plethora of devices have been proposed over the last seven decades for monitoring milk coagulation and curd firming (Gelograph, Formagraph, viscometers, rheometers, etc.), which clearly shows that industrial requirements for cutting selection have not been fully satisfied (O'Callaghan et al. 2002; Nájera et al. 2003; Castillo 2006; Jaramillo et al. 2010; De Marchi et al. 2013). In general, these devices are used to study the rheological properties of gels and are destructive or impractical for inline application. A potential alternative is the introduction of non-destructive sensors, such as optical fiber technology. Non-destructive optical methods have been proposed by some authors (De Marchi et al. 2014; Coppa et al. 2014); Hardy and Fanni 1981; Mc Mahon et al. 1984. The light backscatter sensor proposed by Payne et al. (1993) was developed in cow milk and is currently utilized by several US cheese facilities to predict cutting time. However, the technological suitability of cow's milk differs from those of other milk types such as goat's and sheep's milk or their mixtures (Castillo 2001; Castillo et al. 2000; Jaeggi et al. 2005; Park et al. 2006; Pugliese et al. 1999).

Consequently, it is necessary to evaluate the sensor differences in physical-chemical properties, composition, and coagulation times between milk from different species before the industrial application of the cutting time prediction method based on light backscatter technology. 
Therefore, the goal of this study was to evaluate if an inline fiber optic sensor, measuring near-infrared light backscatter at $880 \mathrm{~nm}$, could be used to efficiently predict both clotting and cutting times during the manufacture of sheep cheese. Without a doubt, an inline sensor with the capability to monitor coagulation of sheep milk will allow the application of corrective actions at a real time, increasing the cheese yield and improving the whole cheese manufacturing process control and thus giving rise to better-quality matured hard or semi-hard sheep cheeses.

\section{Materials and methods}

\subsection{Experimental designs}

A randomized experiment was used to determine the coagulation parameters of sheep milk using four enzyme concentrations $\left(E_{0}=100,200,300\right.$, and $400 \mathrm{mg} \cdot \mathrm{L}^{-1}$ milk $)$ and three replications $(N=a \cdot n=12)$. The same batch of sheep milk was used for the entire experiment. The $\mathrm{pH}$, the temperature $(T)$, and the added calcium chloride concentration (ACCC) were kept constant to reduce the experimental variability $\left(\mathrm{pH}=6.7, T=32{ }^{\circ} \mathrm{C}\right.$, $\mathrm{ACCC}=40 \mathrm{mg} \cdot \mathrm{L}^{-1}$ milk). Sheep milk coagulation was monitored by rheological and optical methods. Simultaneously, both clotting time $\left(t_{\text {clot }}\right)$ and cutting time $\left(t_{\text {cut }}\right)$ were visually determined by an experienced cheese maker. Small-amplitude oscillatory rheology assays were performed using a rheometer, while light backscatter of coagulating milk was measured using a laboratory-scale coagulation tester. Rheological results were used as an objective reference to which visually determined clotting and cutting times could be compared.

\subsection{Milk preparation and coagulation}

Unpasteurized and unhomogenized sheep milk was obtained by mechanical milking from a single sheep herd belonging to the Universitat Autònoma de Barcelona. Milk was vat-pasteurized $\left(63{ }^{\circ} \mathrm{C}, 30 \mathrm{~min}\right)$, immediately refrigerated at $4{ }^{\circ} \mathrm{C}$, and kept stored at this temperature until the test was performed. The experiment was randomly replicated three times using the same batch of milk for all the replications. Each test day, a $300 \mathrm{~mL}$ sample of sheep milk was heated to $32{ }^{\circ} \mathrm{C}$, and the corresponding amount of a commercial calcium chloride solution (35\%, Laboratorios Arroyo, S.A. 39011, Santander, Spain) was added. After thermal equilibrium was achieved, the rennet solution (Renifor-15/E, Lamirsa, Barcelona 100\% chymosin) was added at the target concentration, and the sheep milk was stirred during $30 \mathrm{~s}$. Immediately after stirring, milk samples were split into three aliquots for the rheological $(40 \mathrm{~mL})$, optical (80 $\mathrm{mL}$ ), and visual clotting and cutting time (remaining milk) measurements. The lag time between the enzyme addition and the activation of the respective data acquisition systems was measured with laboratory chronometers.

\subsection{Temperature control}

Precise temperature control is essential for accurate comparison of simultaneous enzymatic reactions. The light backscatter measurement apparatus was coupled to a 
water bath (Julabo MV F-25 Labortechnik GmbH 77960 Seelbach, Germany) having a control accuracy of $\pm 0.01{ }^{\circ} \mathrm{C}$. This water bath was also used to control the temperature of the milk for visual determination of clotting and cutting time. The rheometer had its own system of temperature control (ThermoHaake GmbH Karlsruhe, Germany) having an accuracy of $\pm 0.01{ }^{\circ} \mathrm{C}$ set to $32^{\circ} \mathrm{C}$. The temperature was previously adjusted to the target temperature.

\subsection{Visual clotting and cutting time}

Cheese maker optimal clotting and cutting time ( $t_{\text {clot }}$ and $t_{\text {cut }}$, respectively) were determined visually by introducing a stainless steel spatula into the coagulation vat. The clotting time was measured by pulling out the spatula from the milk, as the time when the drop of milk was reluctant to fall. The cutting time was determined by pulling out the spatula, as the time when there were no coagulum residues on it, and it was completely clean (Nicolau et al. 2011).

\subsection{Rheological analyses}

Small-amplitude oscillatory dynamic trials were carried out with a Couette measuring geometry (Z3DIN) in a ThermoHaakeRS1 (ThermoHaake Gmbh Karlsruhe, Germany) rheometer. The frequency and the strain setup were $1 \mathrm{~Hz}$ and $0.03 \%$, respectively (Hallén et al. 2007). After filling the measuring system, the milk was totally covered with a thin film of vegetable oil to avoid evaporative cooling of the sample during the coagulation. Elastic $\left(G^{\prime}\right)$ and viscous $\left(G^{\prime \prime}\right)$ modulus and the loss tangent $\left(\tan \delta=G^{\prime \prime} / G^{\prime}\right)$ were determined by the software Rheowin (ThermoHaake $\mathrm{GmbH}$ ). The reference rhelogical parameters were clotting time, $t_{\mathrm{G}^{\prime} 1}\left(G^{\prime} \geq 1 \mathrm{~Pa}\right)$, the time when $G^{\prime}$ reached a value of $30 \mathrm{~Pa}\left(t_{\mathrm{G}^{\prime} 30}\right)$, and the time when $G^{\prime}$ reached a value of $65 \mathrm{~Pa}\left(t_{\mathrm{G}^{\prime} 65}\right)$.

\subsection{Monitoring light backscatter profiles}

Sheep milk coagulation was monitored using a near-infrared light backscatter measurement apparatus (CoaguLab Reflectronics Inc. Lexington, KY, USA) as used in Tabayehnejad et al. (2012). Five optical time parameters were defined by the maxima and minima of the derivatives according to Castillo et al. (2006). The times to the first maximum of the first and second derivatives were defined as $t_{\max }$ and $t_{2 \max }$, respectively. The time to the first minimum of the second derivative was defined as $t_{2 \mathrm{~min}}$.

\subsection{Statistical analyses}

All data obtained were processed and analyzed using the Statistical Analysis System SAS $^{\circledR} 9.2$ (Statistical Analyses System Institute, Inc., Cary, NC 27513, 2003-2008). Pearson correlation coefficients $(r)$ were determined by the correlation (CORR) procedure. Student pairwise $t$-test model procedure of SAS (TTEST) was used to determine differences between the optical and rheological time parameters and also the differences between the optically determined and the visually determined total milk-clotting activities. An analysis of variance (ANOVA) was conducted on collected data using the general linear model (GLM) to identify the sources of variation of the studied 
parameters. The linear model used was $Y_{\mathrm{i}}=\mu+E_{\mathrm{i}}+\varepsilon_{\mathrm{i}}$ where Y was the dependent variable studied such as $t_{\max }, t_{2 \max }, t_{2 \min ,} t_{\mathrm{G}^{\prime} 1}, t_{\mathrm{G}^{\prime} 30}, t_{\mathrm{G}^{\prime} 65}, t_{\mathrm{clot}}, t_{\mathrm{cut}}, T_{\text {firm } 30}$, and $T_{\text {firm65 }}, \mu$ was the overall mean, $E_{\mathrm{i}}$ was the enzyme concentration $\left(100,200\right.$ or $300 \mathrm{mg} \mathrm{kg}^{-1}$ milk), and $\varepsilon_{\mathrm{i}}$ was the error term. Least square means (LSM) were considered to be statistically different when $\mathrm{P}<0.05$.

Regression of several different linear models were tested on collected data for predicting visually and rheologically derived clotting and cutting times using the GLM and MAXIMUM $R^{2}$ procedure of SAS. For each prediction, determination coefficient $\left(R^{2}\right)$ and standard error prediction (SEP) were obtained.

\section{Results and discussion}

\subsection{Coagulation sensor calibration for use in sheep milk}

The initial voltage, $V_{0}$, detected by the sensor depends mainly on the type of milk, the fat globule size, and the protein/fat ratio, among other parameters (Castillo 2001). Thus, it is necessary to calibrate the device for the type of milk being monitored. Calibration was done as described by Castillo et al. (2000), adjusting the output voltage to obtain enough response level during coagulation (between 6 and 50\% of the scale depending on fat concentration) without reaching $5 \mathrm{~V}(20 \mathrm{~mA})$ along the whole coagulation process. The blank (not coagulated sheep milk) is usually adjusted to a voltage of $25 \%$ of full-scale value $(2 \mathrm{~V}$ or $8 \mathrm{~mA})$. As the response in sheep milk during coagulation was greater than expected, the initial voltage was adjusted to $\sim 1.8 \mathrm{~V}$. This settled condition allowed getting the right scatter profiles during coagulation in all experiments, within the range of enzyme concentration used in this study.

\subsection{Characterization of the light backscatter profile of sheep milk}

Characterization of the backscatter profile during the coagulation of sheep milk was performed based on the study of optical parameters, $t_{\max }, t_{2 \max }$, and $t_{2 \min }$. Those parameters were selected as potential coagulation indicators based on previous studies carried out with cow and goat milk, which showed that these parameters are related to chemical reactions taking place during milk coagulation (Castillo et al. 2000, 2003, 2006; Saputra 1992).

Preliminary assays carried out with sheep milk allowed obtaining the typical NIR light backscatter profile at $880 \mathrm{~nm}$ corresponding to coagulation of sheep milk. Figure 1 shows this light backscatter ratio profile and its first and second derivatives as a function of time. As shown in Fig. 1, light backscatter ratio increased following a sigmoidal pattern after adding the rennet and determined an inflection point, $t_{\max }$, corresponding to the maximum level of the first derivative. The second derivative of the light backscatter profile versus time also allowed obtaining the two expected optical parameters of interest, $t_{2 \max }$ and $t_{2 \min }$. The average light backscatter ratio increased during the sheep milk coagulation process $(22 \%)$ and was higher than expected. This increase was slightly higher than that observed in goat milk (15-20\%) and lower than in cow milk $(30-50 \%)$. 


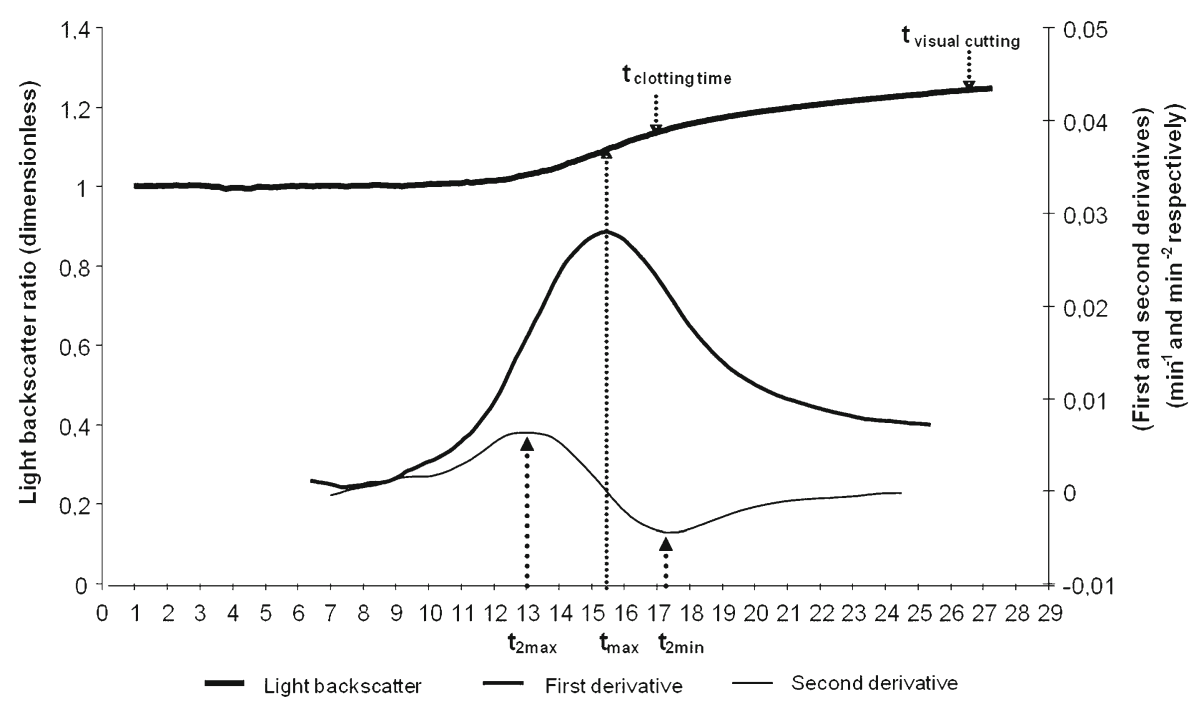

Fig. 1 Light backscatter profile during sheep milk coagulation and its derivatives versus time. The dashed lines identify optical parameters $t_{\max }, t_{2 \max }$, and $t_{2 \min }$ as well as the clotting and cutting times estimated by an experienced cheese maker

Analyzing the standard error for $t_{\max }, t_{2 \max }$, and $t_{2 \min }\left(2^{\prime} 74,2^{\prime} 54\right.$, and $2^{\prime} 87 \mathrm{~min}$, respectively), it can be noticed that this was lower than the standard error observed in visually clotting time $\left(t_{\text {clot }}\right)$ and cutting time $\left(t_{\text {cut }}\right)\left(3^{\prime} 15\right.$ and $3^{\prime} 61 \mathrm{~min}$, respectively), suggesting that monitoring of coagulation by means of optical parameters could contribute to improve the current control of clotting and cutting time determination. As shown in Table 1, observed $r$ values between the three optical parameters $t_{\max }, t_{2 \max }$, and $t_{2 \min }$ and traditional indicators used to control coagulation $t_{\text {clot }}$ and $t_{\text {cut }}$ oscillated between 0.97 and $0.99(p<0.0001)$. It is important to mark that similar correlations were found between these optical parameters and the three gel firmness parameters analyzed-time that takes the $\boldsymbol{G}^{\prime}$ value to reach $\boldsymbol{G}^{\prime}=1 \mathrm{~Pa}\left(t_{\mathrm{G}^{\prime} 1}\right), \boldsymbol{G}^{\prime}=30 \mathrm{~Pa}\left(t_{\mathrm{G}^{\prime} 30}\right)$, and $\boldsymbol{G}$ $'=65 \mathrm{~Pa}\left(t_{\mathrm{G}, 65}\right)$, respectively.

Firmness casein gel times were calculated based on $t_{\mathrm{G}^{\prime} 30}$ and $t_{\mathrm{G}^{\prime} 65}$. Rheological firmness at $30 \mathrm{~min}, T_{\text {firm } 30}$, corresponded to the difference between the rheological

Table 1 Pearson correlation coefficients between optical $\left(t_{\max }, t_{2 \max }\right.$, and $\left.t_{2 \min }\right)$ and visual $\left(t_{\mathrm{clot}}\right.$ and $\left.t_{\mathrm{cut}}\right)$ and rheological $\left(t_{\mathrm{G}^{\prime} 1,} t_{\mathrm{G}^{\prime} 30}\right.$, and $\left.t_{\mathrm{G}^{\prime} 65}\right)$ indicators of sheep milk coagulation $(N=12 ; P<0.0001$ (for definition of parameters, see text))

\begin{tabular}{llll}
\hline & $t_{\max }$ & $t_{2 \max }$ & $t_{2 \min }$ \\
\hline $\begin{array}{l}\text { Visual parameters } \\
t_{\text {clot }}\end{array}$ & 0.998 & 0.997 & \\
$t_{\text {cut }}$ & 0.988 & 0.984 & 0.996 \\
Rheological parameters & & 0.977 \\
$t_{\mathrm{G}^{\prime} 1}$ & 0.994 & 0.992 & \\
$t_{\mathrm{G}^{\prime} 30}$ & 0.9793 & 0.991 & 0.997 \\
$t_{\mathrm{G}^{\prime} 65}$ & 0.991 & 0.990 & 0.996 \\
$T_{\text {firm30 }}$ & 0.977 & 0.977 & 0.996 \\
$T_{\text {firm65 }}$ & 0.981 & 0.980 & 0.989 \\
\hline
\end{tabular}


firming time $t_{\mathrm{G}^{\prime} 1}\left(\boldsymbol{G}^{\prime}>1 \mathrm{~Pa}\right)$ and $t_{\mathrm{G}^{\prime} 30}$. The second firming time calculated was $T_{\text {firm65 }}=$ $t_{\mathrm{G}^{\prime} 65-} t_{\mathrm{G}^{\prime} 1}$. These firming times were strongly correlated with all optical parameters (Table 1), confirming that these parameters not only provide information about clotting and preliminary tridimensional casein network formation but also shed light on the development of casein gel firmness.

\subsection{Comparative study of the visual, rheological, and optical parameters characterizing milk coagulation}

Rennet concentration and replication were selected as the main factors in the preliminary ANOVA model, but replication effect was not significant and was removed from the final model.

The variance analysis confirmed that all of the models were highly significant. $R^{2}$ values for the models corresponding to $t_{\mathrm{max}}, t_{\mathrm{clot},} t_{\text {cut }}, t_{\mathrm{G}^{\prime} 30}, t_{\mathrm{G}^{\prime} 65}$, and $t_{\mathrm{G}^{\prime} 1}$ were 0.990 , $0.996,0.979,0.997,0.998$, and 0.999 , respectively, indicating that the enzyme concentration was capable to explain $(p<0.05)$ the observed experimental variability between $97.7 \%\left(t_{\text {cut }}\right)$ and $99.9 \%\left(t_{\mathrm{G}^{\prime} 1}\right)$. Table 2 shows mean values and standard deviations of studied time parameters. These results show that optical parameters contain information about sheep milk coagulation several minutes before the visual observation by the human eye $\left(t_{\text {clot }}\right)$ and before the rheometer detects the sol-gel transition $\left(t_{\mathrm{G}^{\prime} 1}\right)$. As shown in Table $2, t_{2 \max }$ occurred $\sim 4 \mathrm{~min}$ before $t_{\text {clot }}$ and $t_{\mathrm{G}^{\prime} 1}$. These results agree with previous observations obtained in goat and cow milk (Castillo et al. 2006; Castillo 2001). It is important to notice that the mean value for $t_{\text {cut }}$ (i.e., cutting time visually observed by the cheese maker) appears to be equivalent to the mean value required by the gel to reach firmness $G^{\prime}=65 \mathrm{~Pa}\left(t_{\mathrm{G}^{\prime} 65}\right.$; Table 2$)$.

Differences existing between reference times, $t_{\mathrm{clot}}$ and $t_{\mathrm{G}^{\prime} 1}$, and different optical parameters obtained from the NIR backscatter profile were studied by means of a " $t$ Student" test, and the results are shown in Table 3. All optical parameters were found to be different from $t_{\mathrm{clot}}$ and $t_{\mathrm{G}^{\prime} 1}$ except for the $t_{2 \min }$ parameter. Taking previous studies into account, it is important to notice that the three optical parameters evaluated in sheep milk provided information about micellar aggregation, suggesting that some of these parameters could be good potential predictors for both $t_{\text {clot }}$ and $t_{\mathrm{G}^{\prime} 1}$.

Table 2 Means and standard deviations of optical $\left(t_{\max }, t_{2 \max }\right.$, and $\left.t_{2 \mathrm{~min}}\right)$, visually determined ( $t_{\mathrm{clot}}$ and $\left.t_{\text {cut }}\right)$, and rheological $\left(t_{\mathrm{G}^{\prime} 1,} t_{\mathrm{G}^{\prime} 30 \text {, and }}\right.$ $t_{\mathrm{G}^{\prime} 65}$ ) parameters studied (mean times classified from smallest to largest except for calculated firming times $T_{\text {firm30 }}$ and $T_{\text {firm65 }} ; N=12$ (for definition of parameters, see text))

\begin{tabular}{lll}
\hline & Mean $(\mathrm{min})$ & $\mathrm{SD}(\mathrm{min})$ \\
\hline$t_{2 \max }$ & 15.3 & 2.5 \\
$t_{\max }$ & 17.4 & 2.7 \\
$t_{2 \min }$ & 19.3 & 2.8 \\
$t_{\text {clot }}$ & 19.3 & 3.1 \\
$t_{\mathrm{G}^{\prime} 1}$ & 19.6 & 3.1 \\
$t_{\mathrm{G}^{\prime} 30}$ & 26.8 & 3.8 \\
$t_{\text {cut }}$ & 30.5 & 3.6 \\
$t_{\mathrm{G}^{\prime} 65}$ & 31.8 & 4.3 \\
$T_{\text {firm30 }}$ & 7.2 & 0.7 \\
$T_{\text {firm65 }}$ & 12.2 & 1.2 \\
\hline
\end{tabular}


Table 3 Test " $t$ Student" to evaluate the differences between the main reference clotting indicators: visually determined clotting time $\left(t_{\text {clot }}\right)$ and rheological coagulation time $\left(t_{\mathrm{G}^{\prime} 1}\right)$ and each one of the three optical parameters studied $\left(t_{\max }, t_{2 \max }\right.$, and $\left.t_{2 \min }\right)$

\begin{tabular}{llllll}
\hline $\mathrm{H}_{0}$ & $N$ & Mean (min) & SD (min) & $t$ & $P$ \\
\hline$t_{\mathrm{clot}}-t_{2 \max }$ & 12 & 4.0 & 0.6 & 6.2 & $<0.0001$ \\
$t_{\mathrm{clot}}-t_{\max }$ & 12 & 1.9 & 0.4 & 4.4 & 0.001 \\
$t_{\mathrm{clot}} t_{2 \min }$ & 12 & 0.08 & 0.3 & 0.2 & 0.8337 \\
$t_{\mathrm{G}^{\prime} 1}-t_{2 \max }$ & 12 & 4.2 & 0.6 & 6.6 & $<0.0001$ \\
$t_{\mathrm{G}^{\prime} 1}-t_{\max }$ & 12 & 2.1 & 0.4 & 4.6 & 0.0007 \\
$t_{\mathrm{G}^{\prime} 1}-t_{2 \min }$ & 12 & 0.3 & 0.3 & 0.9 & 0.3461 \\
\hline
\end{tabular}

For definition of parameters, see text

$H_{0}$ null hypothesis, $N$ number of measurements, Mean differences of means between each couple of data, $S D$ standard deviation of the mean, $t$ statistics $t$ Student, $P$ probability of $t$ Student statistics value to be higher than the observed value

\subsection{Influence of enzyme concentration on the visual, rheological, and optical parameters}

Table 4 shows the effect of the enzyme concentration on the different parameters evaluated in the sheep milk. As expected, there were significant reductions of all the time parameters with the increase of the enzyme concentrations.

Storck and Segelcke (1874) observed that the visual clotting time is inversely proportional to the enzyme concentration, a relationship that can be described by the following equation:

$$
t_{\mathrm{c}} \cdot E=K
$$

where $t_{\mathrm{c}}$ is the clotting time, $E$ is the enzymatic activity, and $K$ is a constant. This relation is only reliable in a narrow range of $\mathrm{pH}$, temperature, and enzyme

Table 4 Influence of enzyme concentration on visually determined clotting $\left(t_{\text {clot }}\right)$ and cutting $\left(t_{\text {cut }}\right)$ time, optical $\left(t_{\mathrm{max}}\right)$, and rheological $\left(t_{\mathrm{G}^{\prime} 1}, t_{\mathrm{G}^{\prime} 65}\right)$ time parameters (LSM with the same superscript are not significantly different $(P<0.05)$; number of replications $=3, N=12$. Comparisons are only established between LSM values of the same row)

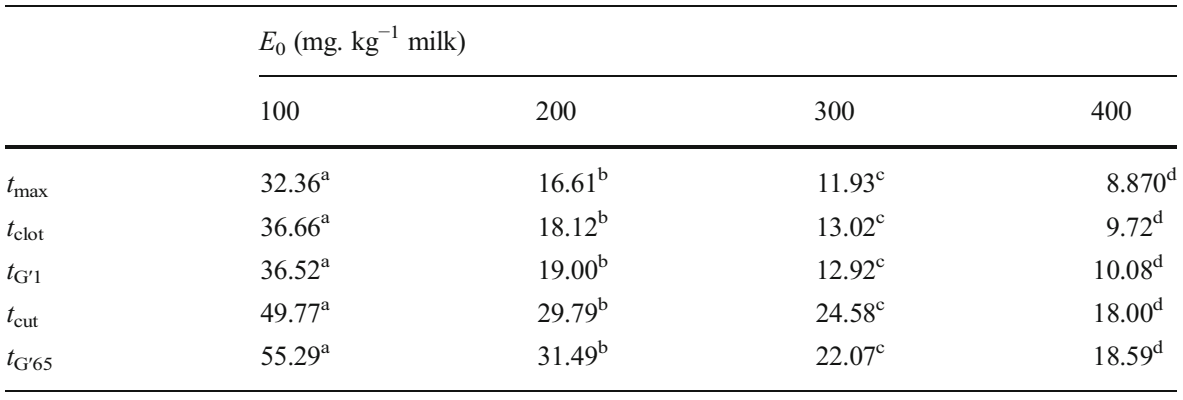

$E_{0}$ enzyme concentration 
concentration. This is the reason why Holter (1932) proposed a new expression, which was modified later by Foltmann (1959);

$$
t_{\mathrm{c}}=(a /[E])+b,
$$

where $t_{\mathrm{c}}$ is the clotting time, $[E]=$ enzyme concentration, $a$ is a constant, and $b$ represents the minimum clotting time when $[E] \rightarrow \infty$. According to Eq. 2, the plotting of time versus the inverse of the enzyme concentration should be linear. Results obtained show that both rheological clotting times and fiber optic sensor indicators of clotting time matched perfectly, as expected, with the Foltmann equation (Fig. 2). The light scatter parameters $t_{2 \max }$ and $t_{2 \min }$ also followed Foltmann's equation.

Results showed that the NIR backscatter sensor had a consistent response to the kinetic changes induced by the variation on the enzyme concentration during the sheep milk coagulation process in the experimental conditions assayed. There is relevant application potential for this optical technology to predict the clotting time "inline" due to its non-invasive character, the strong and consistent response to the different levels of enzyme concentration, and the simplicity of direct implementation of the optical fiber sensor in the wall of the cheese vat for real-time monitoring of sheep milk coagulation during the cheese-making process.

\subsection{Prediction equations for clotting and cutting time using optical parameters as predictors}

Taking into account preliminary experiences and the results obtained in optical monitoring of sheep milk coagulation, where the correlation between the parameters analyzed was strong (Table 1), it was possible to obtain prediction equations for time parameters $t_{\mathrm{clot}}, t_{\mathrm{cut}}, t_{\mathrm{G}^{\prime} 1}, t_{\mathrm{G}^{\prime} 30}$, and $t_{\mathrm{G}^{\prime} 65}$ using only the optical parameters as predictors.

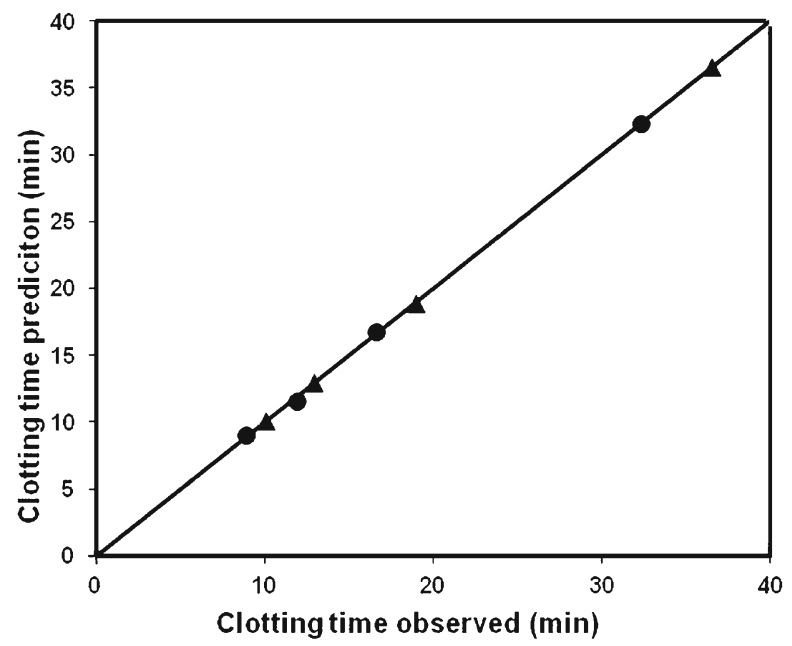

Fig. 2 Regression of optical $\left(t_{\max }\right)$ and rheological $\left(G^{\prime}>1 \mathrm{~Pa}\right)$ clotting time indicators observed experimentally and its prediction by Foltmann equation in terms of enzyme concentration. Filled circle optical clotting time (backscatter NIR), filled triangle rheological clotting time. Regression parameters for $t_{\max }: a=0.31, b=$ $1.26, R^{2}=0.99$; for $G^{\prime}: a=0.35, b=1.25, R^{2}=0.99$ ) 
Table 5 Algorithms for prediction of the technological parameters studied, $t_{\mathrm{G}^{\prime} 1}, t_{\mathrm{G}^{\prime} 30}, t_{\mathrm{G}^{\prime} 65}, t_{\mathrm{clot}}$, and $t_{\text {cut }}$, in sheep milk using a fiber optic milk coagulation measurement apparatus determining near-infrared light backscatter $(N=12)$

\begin{tabular}{llclll}
\hline Identification & Model & $\beta_{0}$ & $\beta_{1}$ & $R^{2}$ & SEP (min) \\
\hline $\mathrm{I}^{* * * *}$ & $t_{\mathrm{clot}}=\beta_{0}+\beta_{1} t_{\max }$ & $-0.61^{\mathrm{ns}}$ & $1.15^{* * *}$ & 0.997 & 0.663 \\
$\mathrm{II}^{\text {I*** }}$ & $t_{\mathrm{cut}}=\beta_{0}+\beta_{1} t_{\max }$ & $7.81^{* * *}$ & $1.30^{* * *}$ & 0.977 & 2.012 \\
$\mathrm{III}^{* * * *}$ & $t_{\mathrm{G}^{\prime} 1}=\beta_{0}+\beta_{1} t_{2 \min }$ & $-1.15^{\mathrm{ns}}$ & $1.08^{* * *}$ & 0.993 & 0.936 \\
$\mathrm{IV}^{* * * *}$ & $t_{\mathrm{G}^{\prime} 30}=\beta_{0}+\beta_{1} t_{2 \min }$ & $0.78^{\mathrm{ns}}$ & $1.35^{* * *}$ & 0.993 & 1.217 \\
$\mathrm{~V}^{* * *}$ & $t_{\mathrm{G}^{\prime} 65}=\beta_{0}+\beta_{1} t_{2 \min }$ & $2.86^{*}$ & $1.50^{* * *}$ & 0.992 & 1.400 \\
\hline
\end{tabular}

$\beta_{0}$ and $\beta_{1}$ regression coefficients, $\mathrm{R}^{2}$ determination coefficient, SEP standard error of prediction, $t_{G^{\prime} l}$ time when $\boldsymbol{G}^{\prime}$ reached $1 \mathrm{~Pa}, t_{G^{\prime} 30}$ time when $\boldsymbol{G}^{\prime}$ reached $30 \mathrm{~Pa}, t_{G^{\prime} 65}$ time when $\boldsymbol{G}^{\prime}$ reached $65 \mathrm{~Pa}, t_{\text {clot }}$ visually determined clotting time, $t_{\text {cut }}$ visually determined cutting time, $n s$ not significant at $95 \%$

*Significant at $95 \%$; ** significant at $99 \%$; *** significant at $99.9 \%$

Clotting time indicators, $t_{\mathrm{G}^{\prime} 1}$ and $t_{\mathrm{clot}}$, and cutting time parameters, $t_{\mathrm{G}^{\prime} 30}, t_{\mathrm{G}^{\prime} 65}$, and $t_{\text {cut }}$, were successfully predicted using one optical parameter $\left(t_{\max }\right.$ or $\left.t_{2 \min }\right)$ with $R^{2}>$ 0.98 and SEP values ranging from 0.66 to $2.01 \mathrm{~min}$.

The best one-parameter models using the MAXIMUM $R^{2}$ procedure of SAS for predicting the technological parameters mentioned above are shown in Table 5.

As shown in Table 5, the best model to predict coagulation parameters subjectively selected by the operator $\left(t_{\text {clot }}, t_{\text {cut }}\right)$ were models I and II. Both models used $t_{\text {max }}$ as light backscatter predictor. Surprisingly, the best models to predict the measured rheological parameters $\left(t_{\mathrm{G}^{\prime} 1}, t_{\mathrm{G}^{\prime} 30}\right.$, and $\left.t_{\mathrm{G}^{\prime} 65}\right)$ were models III, IV, and V, all of which used $t_{2 \min }$ as optical predictor.

On the other hand, it was observed that the accuracy of the estimations was better for $t_{\text {clot }}$ (SEP 0.663) and the rheological parameters (SEP 0.936-1.4) than for $t_{\text {cut }}(2.012)$, which was attributed to the large variability of visual cutting time determination (Table 5). The SEP for estimation of $t_{\text {cut }}$ was almost double than that observed for

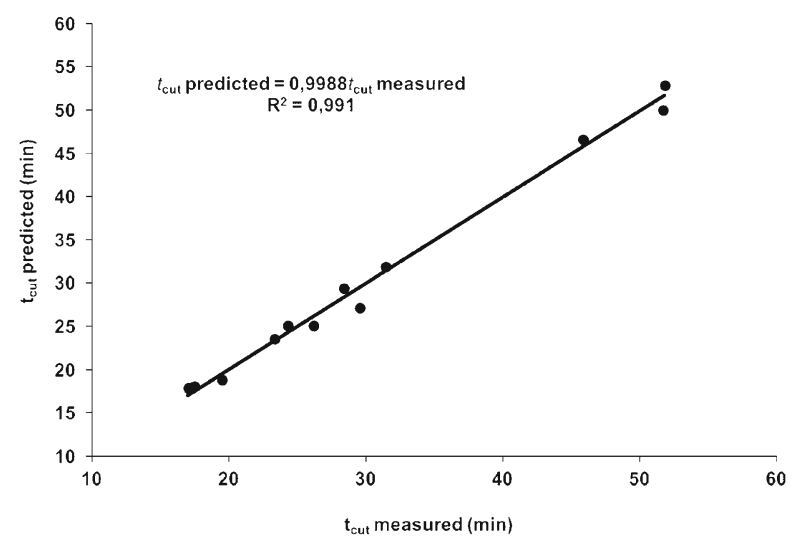

Fig. 3 Plot of predicted vs. visually observed cutting time. Cutting time values were estimated based on $\mathrm{ACCC}, t_{\max }$, and $t_{2 \max }(\operatorname{model} \mathrm{VI})$ 
estimation of $t_{\mathrm{G}^{\prime} 30}$. These results were expected as a result of the large subjectivity of such a measurement compared to the more objective rheological estimation of cutting.

Finally, incorporation of more parameters into the models such as ACCC and $t_{2 \max }$ allowed improving the determination coefficient and the SEP of predictions. For instance, introduction of ACCC and $t_{2 \max }$ into model II (model VI) for $t_{\text {cut }}$ prediction increased $R^{2}$ from 0.977 (model II) up to 0.991 (model VI), while SEP decreased by $\sim 50 \%$ (from $2.012 \mathrm{~min}$ - model II- to $1.176 \mathrm{~min}$ - model VI) (Fig. 3).

\section{Conclusions}

As observed in preliminary studies with cow and goat milk, the light backscatter sensor had a sigmoidal response with an inflection point (corresponding to the maximum level of the first derivative) during the cheese-making process when using sheep milk; thus, it is possible to obtain the same clotting and cutting time prediction parameters as those used in cow and goat milk. During the sheep milk coagulation, light backscatter showed typically increased values, oscillating between goat's and cow's values.

Optical prediction parameters had a consistent response to the kinetic changes induced by the different levels of enzyme concentration during the milk coagulation process in the experimental tested conditions (i.e., they follow Foltmann equation). Moreover, it is important to note that the optical parameters generated during the sheep milk coagulation were obtained before than the rheological ones or the first flocks of casein were visible to the human eye. The prediction equations allowed the subjective clotting and cutting time established by the cheese-maker to be predicted with a high correlation coefficient.

The use of a light backscatter sensor to monitor sheep milk coagulation and predict both clotting and cutting time shows potential to assist sheep cheese manufacturers in achieving a better homogeneity in the end product.

Acknowledgments Funding for this research was provided by the Spanish national project entitled "Desarrollo e integración para el control de la producción de queso manchego con sensores de coagulación" CDTI, 2008-2009, and the Catalan projects "Sistema de predicció del temps de tall en formatges elaborats amb barreja de llet de vaca, ovella i cabra mitjançant dispersió d'infraroig proper" EvalXaRTA. 2011 UAB2 306260 and Desenvolupament i integració pel control de producción de formatge Manchego amb sensors de coagulació" EvalXaRTA. 2010 UAB1 28-06.

Conflict of interest The authors of this work, Nicolau, N., Buffa, M., O'Callaghan, DJ., Guamis, B., and Castillo, M., wish to confirm that there are no known conflicts of interest associated with the publication Estimation of clotting and cutting times in sheep cheese manufacture using NIR light backscatter and that there has been no significant financial support for this work that could have influenced its outcome.

Human and animal rights This article does not contain any studies with human or animal subjects performed by any of the authors.

\section{References}

Castillo M (2001) Cutting time prediction in cheese making by backscatter of near infrared radiation. PhD diss Food Technology, Human Nutrition and Bromatology Dept, University of Murcia, Murcia

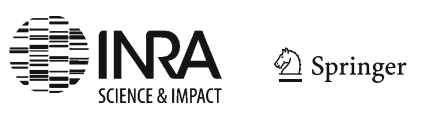


Castillo M (2006) Cutting time prediction methods in cheese making. Encycl Agric Food Biol Eng. doi:10. 1081/e-eafe-120040365

Castillo M, Payne FA, Hicks CL, López MB (2000) Predicting cutting and clotting time of coagulating goat's milk using diffuse reflectance: effect of $\mathrm{pH}$, temperature and enzyme concentration. Int Dairy J 10:551562

Castillo M, Payne FA, Hicks CL, Laencina J, López M (2003) Effect of protein and temperature on cutting time prediction in goat's milk using an optical reflectance sensor. J Dairy Res 70:205-215

Castillo M, Lucey JA, Payne FA (2006) The effect of temperature and inoculum concentration on rheological and light scatter properties of milk coagulated by a combination of bacterial fermentation and chymosin. Cottage cheese-type gels. Int Dairy J 15:131-146

Coppa M, Revello-Chion A, Giaccone D et al (2014) Comparison of near and medium infrared spectroscopy to predict fatty acid composition on fresh and thawed milk. Food Chem 150:49-57. doi:10.1016/j. foodchem.2013.10.087

De Marchi M, Toffanin V, Cassandro M, Penasa M (2013) Prediction of coagulating and noncoagulating milk samples using mid-infrared spectroscopy. J Dairy Sci 96:4707-4715. doi:10.3168/jds.2012-6506

De Marchi M, Toffanin V, Cassandro M, Penasa M (2014) Invited review: mid-infrared spectroscopy as phenotyping tool for milk traits. J Dairy Sci 97:1171-1186. doi:10.3168/jds.2013-6799

Dubeuf J-P, Ruiz Morales FA, Castel Genis JM (2010) Initiatives and projects to promote the Mediterranean local cheeses and their relations to the development of livestock systems and activities. Small Rumin Res 93(2-3):67-75

Foltmann B (1959) On the enzymatic and the coagulation stages of the renneteing process. 15th International Dairy Congress, vol. 2, London, pp 655-661

Gunasekaran S, Ay C (1996) Milk coagulation cut-time determination using ultrasonics. J Food Process Eng 19:63-73

Hallén E, Allmere T, Näslund J, Andrén A, Lundén A (2007) Effect of polymorphism of milk proteins on rheology of chymosin-induced milk gels. Int Dairy J 17:791-799

Hardy J, Fanni J (1981) Application of reflection photometry to the measurement of milk coagulation. J Food Sci 46:1956-1957

Holter H (1932) Uber die Labwirkung. Biochem Z 255:160-188

Hori T (1985) Objective measurements of the process of curd formation during rennet treatment of milks by the hot wire method. J Food Sci 50(4):911-917

Jaeggi JJ, Wendorff WL, Romero J, Berger YM, Johnson ME (2005) Impact of seasonal changes in ovine milk on composition and yield of a hard-pressed cheese. J Dairy Sci 8:1358-1363

Jaramillo DP, Buffa MN, Rodriguez M et al (2010) Effect of the inclusion of artichoke silage in the ration of lactating ewes on the properties of milk and cheese characteristics during ripening. J Dairy Sci 93:14121419. doi:10.3168/jds.2009-2740

Jimenez-Marquez SA, Thibault J, Lacroix C (2005) Prediction of moisture in cheese of commercial production using neural networks. Int Dairy J 15:1156-1174. doi:10.1016/j.idairyj.2004.12.005

Mc Mahon DJ, Brown RJ, Ernstrom CA (1984) Enzymic coagulation of milk casein micelles. J Dairy Sci 67: 745-748

Nájera AI, de Renobales M, Barron LJR (2003) Effects of $\mathrm{pH}$, temperature, $\mathrm{CaCl}_{2}$ and enzyme concentrations on the rennet-clotting properties of milk: a multifactorial study. Food Chem 80:345-352. doi:10.1016/ S0308-8146(02)00270-4

Nicolau N, Castillo M, Buffa M, O’Callaghan DJ, Guamis B (2011) Light scatter estimation of clotting and cutting time in sheep cheese manufacture. ICEF'11 May 22-26, Athens, Greece

O'Callaghan D, O’Donnell C, Payne F (2002) Review of systems for monitoring curd setting during cheese making. Int Dairy J 55:65-74

Park YW, Juárez M, Ramos M, Haenlein GFW (2006) Physico-chemical characteristics of goat and sheep milk. Small Rumin Res 68:88-113

Payne FA, Hicks CL, Shen PS (1993) Predicting optimal cutting time of coagulating milk using diffuse reflectance. J Dairy Sci 76(1):48-61

Pugliese C, Acciaioli A, Rapaccini S, Parisi G, Franci O (1999) Evolution of chemical composition, somatic cell count and renneting properties of the milk of Massese ewes. Small Rumin Res 35:71-80

Rovira S, Garcia V, Laencina J, Belen Lopez M (2013) Microstructure of industrially manufactured goat cheese Queso de Murcia al Vino during synaeresis. Int J Dairy Technol 66:382-389. doi:10.1111/14710307.12050

Saputra D (1992) Analysis of enzymatic hydrolysis of milk using diffuse reflectance of near infrared radiation. $\mathrm{PhD}$ thesis, University of Kentucky, Kentucky 
Storck V, Segelcke T (1874) Milchforsch, Milchprax 3:997 (cited by McMahon DJ, Brown RJ (1983) Milk coagulation time: linear relationship with inverse of rennet activity. J Dairy Sci 66:341-344

Tabayehnejad N, Castillo M, Payne FA (2012) Comparison of total milk-clotting activity measurement precision using the Berridge clotting time method and a proposed optical method. J Food Eng 108: 549-556. doi:10.1016/j.jfoodeng.2011.09.009

Van Hooydonk ACM, Van den Berg G (1988) Control and determination of the curd-setting during cheesemaking. International Dairy Federation (IDF B-Doc 225) 